We welcome letters to the Editor concerning articles which have recently been published. Such letters will be subject to the usual stages of selection and editing; where appropriate the authors of the original article will be offered the opportunity to reply.

Letters should normally be under $\mathbf{3 0 0}$ words in length, doublespaced throughout, signed by all authors and fully referenced. The edited version will be returned for approval before publication.

(C)2004 British Editorial Society of Bone and Joint Surgery doi:10.1302/0301-620X.86B3.15452 \$2.00

J Bone Joint Surg [Br] 2004;86-B:464-5.

\section{Complete remodelling of displaced fractures of the neck of the phalanx}

Sir,

I read with interest the paper by Hennrikus and Cohen ${ }^{1}$ in the March 2003 issue entitled 'Complete remodelling of displaced fractures of the neck and the phalanx'.

I recently treated a nine-year-old boy with a displaced angulated fracture of the neck of the right ring finger proximal phalanx. He presented two weeks after his injury.

Neither the patient or his family wanted surgery or a reduction manoeuvre. A cast was applied with the interphalangeal joints in extension and the metacarpal phalangeal joints flexed. The patient removed the cast after a week but returned 16 weeks after injury. The fracture had healed and most of the deformity had remodelled.

The patient and parents had no complaints. The range of movement was normal and there was no cosmetic deformity. It appears satisfactory remodelling can occur up to age nine in boys.

\section{J. W. PRITCHETT, MD FACS \\ Pacific Medical Center \\ Seattle, USA.}

1. Hennrikus WL, Cohen MR. Complete remodelling of displaced fractures of the neck of the phalanx. J Bone Joint Surg [Br] 2003;85-B:273-4.

\section{Author's reply:}

Sir,

We are delighted to read of Dr Pritchett's case of near-complete remodelling of a displaced fracture of the neck of the proximal phalanx of the ring finger in a nine-year-old boy. We concur with Dr Pritchett's conclusion that satisfactory remodelling can occur up to age nine in boys. Indeed, the follow-up of this case was only 16 weeks. A longer period of follow-up may demonstrate complete remodelling. Dr Pritchett's case lends additional support to our premise that, in children, spontaneous remodelling of phalangeal neck fractures can occur despite the distance of the fracture from the physis.

W. L. HENNRIKUS, MD

Children's Hospital

California, USA.

\section{A strategy for reducing blood-transfusion requirements in elective orthopaedic surgery}

Sir,

We read with interest the paper by Helm et al, ${ }^{1}$ in the May 2003 issue entitled 'A strategy for reducing blood-transfusion requirements in elective orthopaedic surgery: audit of an algorithm for arthroplasty of the lower limb'.

Reducing the blood transfusion requirements is a very topical issue at the present time. We are surprised that they have not been able to use autologous re-infusion drains because of financial restraints. The algorithm obviously works but would appear to be quite time consuming. We have performed an audit and have shown them to be cost effective as well as reducing the transfusion rate.

In our unit autologous drains have been used for several years in patients undergoing knee arthroplasty. It is now very rare for such a patient to need a homologous blood transfusion. Newman et $\mathrm{al}^{2}$ showed the benefits of this technique in 1997 . We have recently performed an audit to see if the autologous drains would be effective in hip arthroplasty.

We retrospectively reviewed 43 patients and the overall transfusion rate was $23 \%$ (0.49 units per patient). We then started using the Bellovac autologous drainage system (Astra, Gloucester, UK) The transfusion rate in 35 patients has reduced to $5.8 \%(0.15$ units per patient). We now use them routinely. They also only need to be grouped and saved rather than cross-matched. The cost of a unit of blood in our hospital is approximately $£ 130$ and the cost of the drain is $£ 45$ per patient. There are financial savings to be made using this system. We have found the system to be very easy to use and we have not had any adverse events from their use. We would strongly recommend their use and they would appear to be simpler and easier than the algorithm suggested by Helm et al. ${ }^{1}$

\section{S. W. STURDEE, MB ChB, MRCS, MRCS Ed}

D. J. BEARD, MB ChB,${ }^{3}$ FRCS

Airedale General Hospital,

West Yorkshire, UK.

1. Helm AT, Karski MT, Parsons SJ, Sampath JS, Bale RS. A strategy for reducing blood-transfusion requirements in elective orthopaedic surgery: audit of an algorithm for arthroplasty of the lower limb. J Bone Joint Surg [Br]2003:85-B:484-9.

2. Newman JH, Bowers M, Murphy J. The clinical advantages of autologous transfusion: a randomized, controlled study after knee replacement. J Bone Joint Surg [Br] 1997:79-B:630-2

\section{Author's reply:}

Sir,

May I thank the authors for their interest in our paper. Their figures showing a reduction in transfusion rates following the introduction of autologous re-infusion drains are interesting. It is unfortunate that when we began our audit we did not have re-infusion drains at our disposal, as it had been considered by higher authorities that these were too expensive. I think it is clear from the authors figures 
that this is not the case. As stated in the final paragraph of our discussion, we believe that if we were able to use re-infusion drains and our protocol, the numbers of allogenic units transfused would be even further reduced. Our algorithm certainly does work and I do not agree that it is time consuming. It would be useful to audit again the number of units of blood transfused in lower limb arthroplasties using both our protocol and reinfusion drains.

\section{A. T. HELM, MRCS \\ Royal Preston Hospital, Preston, UK.}

\section{Complications of arthroscopic reconstruction of the anterior cruciate ligament}

Sir,

We read with interest by Allum ${ }^{1}$ in the January 2003 issue entitled 'Complications of arthroscopic reconstruction of the anterior cruciate ligament'.

The article highlighted the fact that tunnel misplacement is the most common cause of error in this operation. It stated that the most common fault was to place the femoral tunnel too anteriorly. The relatively high incidence of this error has made the accurate documentation of tunnel position imperative, not only for clinical review, but also medicolegally. It is commonplace to use radiographs to record the placement of tunnel, and this practice has been advocated as mandatory by some authors. ${ }^{2}$ In day case surgery, however, the logistics of obtaining immediate post-operative films may cause a delay in discharge of the patient. The authors have found the following technique useful in its place.

A view from a low anteromedial port may look directly up the femoral tunnel, and with the knowledge of the tunnel's diameter, the distance to the posterior wall is easily measured as the minimum of 1 to $2 \mathrm{~mm}$.

A high lateral port will offer a view of the extended knee that allows impingement to be detected. Thereby the placement of the tibial tunnel is also checked, and recorded.

The use of this method has several advantages over the use of radiographs. The technique is immediate, and intra-operative. It is not fraught with the errors of radiographic measurements.

If these two arthroscopic images are captured and printed, then the need for routine post-operative radiography is obviated.

\section{R. W. SOUTHGATE}

M. D. HOLT

Morriston Hospital, Swansea, UK.

1. Allum R. Complications of arthroscopic reconstruction of the anterior cruciate ligament. J Bone Joint Surg [Br] 2003;85-B:12-6.

2. Topliss C, Webb J. An audit of tunnel position in anterior cruciate ligament reconstruction. The Knee 2001:8:59-63.

\section{Author's reply:}

Sir,

I would like to thank Messrs Southgate and Holt for their interest in my paper.

A photographic record is useful but it is not always easy to interpret and it is difficult to obtain accurate measurements. A radiograph will clearly show both tibial and femoral tunnels together with the fixation devices and measurements can be taken if necessary. Radiographs can always be carried out as an outpatient.

\section{R. ALLUM, FRCS}

Farnham Common, Buckinghamshire, UK. 